\title{
Effect of Cooking Temperature on Residual Oxytetracycline Hydrochloride in Cooked Chicken
}

\author{
Ramdane MOHAMED SAID ${ }^{1 *}$; Houssem SLAMA ${ }^{1}$ \\ ${ }^{1}$ Department of Biology and Cellular Physiology, Faculty of Natural and Life Sciences, \\ Saad Dahlab Blida 1 University, Algeria \\ *corresponding author: rmohamedsaid@yahoo.fr
}

Bulletin UASVM Animal Science and Biotechnologies 76(1)/ 2019

Print ISSN 1843-5262; Electronic ISSN 1843-536X

DOI:10.15835/buasvmcn-asb: 2018-0014

\begin{abstract}
The concentration in samples cooked at $115^{\circ} \mathrm{C}$ is of $73.71 \mu \mathrm{g} / \mathrm{mg}$ either $49.40 \%$ reduction and a $145{ }^{\circ} \mathrm{C}$ is $66.03 \mu \mathrm{g} / \mathrm{mg}$ representing a $54.68 \%$ reduction. Bake at $145^{\circ} \mathrm{C}$ during 20 minutes is enough to destroy almost $55 \%$ of the initial quantity of residues in chicken hence HCL OTC residues are degradable thermo.
\end{abstract}

Keywords: antibiotics, residues, livestock, chicken meat

\section{Introduction}

The aim of this study is the detection and the quantification of «Oxytetracycline Hydrochloride» antibiotic residues in cooked chicken meat and the heat effect on its molecule.

Few works described the thermal analysis of theseantibiotics. These include the thermostability of oxytetracycline,tetracycline and doxytetracycline at high and ultrahigh temperatures $\left(110-140^{\circ} \mathrm{C}\right)$, showing a first order reaction kinetic (Hassani et al., 2008).

Oxytetracycline Hydrochloride (OTC $\mathrm{HCl}$, $\mathrm{C}_{22} \mathrm{H}_{25} \mathrm{ClN}_{2} \mathrm{O}_{9}$ ) is commonly used in poultry farming for preventive and curative treatment but mainly as a growth factor in Algeria.

Tetracycline compounds (TCs) are common antibiotics used for human therapy, for veterinary purposes and as agricultural feed additives (Coustès, 2016, Li et al., 2011).

However, the misuse of this compound may result in its presence in chicken meat, especially if waiting times are not respected, and may therefore pose a threat to the consumers health.

Moreover, the abundant and improper use of TCs may result in the presence of their residues in edible animal tissues, which can be toxic and potentially cause allergic reactions (Cetinkayaa et al., 2012). It is recalled that the maximum residue limits (MRL) for oxytetracycline (OTC) are $100 \mu \mathrm{g} \cdot \mathrm{kg}^{-1}$ for chicken muscle (EU Regulation 37/2010) (Shahid et al., 2007).

\section{Material and methods \\ Analysis of turbidity}

The detection of OTC $\mathrm{HCl}$ residues in fresh and turbidimetric chicken is based on the following principle: the microorganisms growth in a clear liquid medium (meat juice) containing a constant concentration of antibiotic residues will result in by a «change in the environment turbidity». This change in turbidity or absorbance is measured using a spectrophotometer. The recorded absorbance is determined by the number of microorganisms present in the solution. Thus, the decrease in absorbance reflects the effect of the antimicrobial substance on the bacterial population present in the sample. The time required to achieve a certain absorbance under well-defined conditions may be proportional to the initial load of micro-organisms inoculated into the medium. Absorbance is measured at $530 \mathrm{~nm}$ (Jorgensen and Schulz, 1985). The turbidimetry technique requires a basic step which is the 
extraction of the antibiotic contained in the meat, before reading on the spectrophotometer.

\section{Analysis by HPLC}

The quantification of the content of OTC $\mathrm{HCl}$ residues of fresh and cooked chicken by reverse phase HPLC is based on the following principle: the sample is associated with a solvent which passes under pressure a column containing what is called the stationary phase, a gel that has the property of retaining the molecules that pass through it. Depending on the affinity between the compounds of the sample and the stationary phase, these compounds will be retained more or less long in the column before coming out and being measured. A detector continuously monitors the liquid at the outlet of the column to detect the presence of the compounds. The most common is a UV-visible spectrophotometer, which measures the absorption of light by the product. The detector is linked to a computer that can display a quantization graph as a function of time. Each type of molecule transported by the mobile phase will appear as a peak in the graph whose area allows to quantify the quantity of these molecules (Meyer, 2010).

The column used is composed mainly of silicas grafted by linear chains of 18 carbon atoms (C18). This phase is apolar (hydrophobic) and therefore requires a polar solvent to convey the sample (acetonitrile, methanol, water). The polar compounds will be eluted first and the apolar (hydrophobic) compounds will be retained (Meyer, 2010). OTC HClis a good example of these compounds (Aggarwal, 2015). The residues extraction from the meat is also required in the HPLC analysis. A volume of $20 \mu \mathrm{L}$ of standard OTC $\mathrm{HCl}$ solution and from each sample is injected.

\section{Kinetics of the molecule}

OTC $\mathrm{HCl}$ heating: a volume of $50 \mathrm{~mL}$ of OTC $\mathrm{HCl}\left(0.6 \mathrm{mg} \cdot \mathrm{mL}^{-1}\right)$ is poured into 5 test tubes. Each tube is placed in a « bain-marie » preheated to a temperature and heating time according to Table 1.

Study of the OTC $\mathrm{HCl}$ molecule stability after heat treatment using the Agar diffusion method

A filter paper disk containing amounts of antibiotic is placed on a solid medium which has been widely seeded with test organisms. After incubation, the diameter of the clear inhibition
Table 1: Temperatures and heating times of OTC $\mathrm{HCl}$ solutions

\begin{tabular}{|c|c|c|c|}
\hline Tube & $\begin{array}{l}\text { Volume } \\
(\mathrm{mL})\end{array}$ & $\begin{array}{c}\text { Heating } \\
\text { temperature }\left({ }^{\circ} \mathrm{C}\right)\end{array}$ & $\begin{array}{c}\text { Heating } \\
\text { time (min) }\end{array}$ \\
\hline \multicolumn{4}{|c|}{ Control } \\
\hline 1 & \multirow{5}{*}{10} & 45 & 60 \\
\hline 2 & & 60 & 55 \\
\hline 3 & & 85 & 50 \\
\hline 4 & & 100 & 40 \\
\hline 5 & & 120 & 30 \\
\hline
\end{tabular}

zone surrounding the disc is used to measure the antibiotic inhibitory potencyagainst the test organism (Jawetz et al., 1999). In this experiment, the aim is to study the heat effecton the inhibitory activity of the OTC $\mathrm{HCl}$ molecule by heating at different temperatures for specific times, which results in variations in the inhibition zone diameters.

\section{Biological material}

Strains: suspension of Staphyloccocus aureus (ATCC $6538 \mathrm{P}$ ) is supplied by the laboratory.

Meat: 20 broilers, 35 days old, are taken from a farm in Medea (Algeria). Fifteen of them are isolated and put in a cage. OTC $\mathrm{HCl}$ is intentionally introduced into their diet at high doses $(500 \mathrm{mg})$ for 5 days (Protocol :20 mg of oxytetracycline by kg of body weight per day for 3 to 5 days in drinking water, or about $400 \mathrm{mg}$ of powder for oral solution per litre of drinking water). The waiting time was not respected to ensure the presence of residues in the muscle. it is to be on to find this residue of antibiotics in meat and see the effect of cooking on this molecule of oxytetracycline. it's from 35 days the chicken can be sold so the meat eating can hold at this age there.

The hygienic conditions of slaughter, evisceration and cutting have been respected in order to avoid any risk of contamination. The chicken part of interest is the wishbone. Ten wishbones of the treated animals are cooked: 5 in a pressure cooker at $115^{\circ} \mathrm{C}$ for $35 \mathrm{~min}\left(\mathrm{~S}(+)_{115}\right)$, the others in an oven at $145^{\circ} \mathrm{C}$ for $20 \mathrm{~min}\left(\mathrm{~S}(+)_{145}\right)$. A negative sample $S(-)$ and a positive sample $S(+)$ without heating were also used. Fifty grams portions of each fishbone are minced under sterile conditions. The samples, distributed as indicated in Table 2, are placed in sterile boxes at $4^{\circ} \mathrm{C}$. 
Table 2: Sampling

\begin{tabular}{cccc}
\hline Sample & $\begin{array}{c}\text { Quantity } \\
(\mathrm{g})\end{array}$ & $\begin{array}{c}\text { Cooking } \\
\text { temperature }\left({ }^{\circ} \mathrm{C}\right)\end{array}$ & $\begin{array}{c}\text { Duration } \\
(\mathrm{min})\end{array}$ \\
\hline $\mathrm{S}(-)$ & 250 & & \\
\hline $\mathrm{S}(+)$ & 250 & & \\
\hline $\mathrm{S}(+)_{115}$ & 250 & 115 & 35 \\
\hline $\mathrm{S}(+)_{145}$ & 250 & 145 & 20 \\
\hline
\end{tabular}

\section{Results of turbidimetric detection}

The visual appearance of the solutions after incubation is presented in Figure 1.

This figure shows a difference in the solutions turbidity which intensifies when the antibiotic concentration in the mixture is low. The nearly unnoticed disorder in the $\mathrm{S}(+)$ and $\mathrm{S}(+)_{115}$ solutions shows the presence of residues in the meat of large quantities treated' animals.

The average absorbance values recorded in two tests are presented in Table 3.

The lowest absorbance value of the $\mathrm{S}(+)$ solution have confirmed the presence of a highantibiotic concentration in the positive sample. Conversely, the highest absorbance value of the $\mathrm{S}(-)$ solution have confirmed the absence of antibiotic in the sample. The comparison of the absorbance of the $\mathrm{S}(+)_{115}, \mathrm{~S}(+)_{145}$ and $\mathrm{S}(+)$ solutions have shown that the heat has an effect on the concentration of antibiotic present in the muscle. Indeed, the concentration of this ATB versus absorbance decreases as the cooking temperatureincreases. The concentration in these last two samples is less than $100 \mu \mathrm{g} \cdot \mathrm{mL}^{-1}$ since their absorbance is relatively high compared to that of the standard OTC $\mathrm{HCl}$ solution $\left(100 \mu \mathrm{g} \cdot \mathrm{mL}^{-1}\right)$.

The absorbances of the samples $\mathrm{S}(+), \mathrm{S}(+)_{115}$, $\mathrm{S}(+)_{145}$ and standard OTC $\mathrm{HCl}$ solutions decreased because of the continuous inhibitory action of the antibiotics against the germs in these solutions. On the other hand, for the negative sample, the absorbance value has increased, so the germs can always multiply in the absence of antibiotic.

\section{Quantification results by reverse phase HPLC}

The following figures represent the peaks obtained after injection of the standard OTC $\mathrm{HCl}$ solution and from solutions containing the positive samples and the negative sample.

The injection of the standard solution OTC $\mathrm{HCl}$ (0.4 mg.mL $\left.{ }^{-1}\right)$ has given a peak in the chromatogram after $2 \mathrm{~min}$ of analysis (Figure 2A), which is consistent with the OTC $\mathrm{HCl}$ analysis parameters mentioned in « Material and methods » paragraph. The area of this peak is 11645 293. No peak was recorded (Figure 2B) by injecting the S(-) solution which confirms the absence of the antibiotic in the negative sample.The $\mathrm{S}(+)$ solution (Figure 2C) has given a peak, area 4735 657, after 1.97 min of analysis. This is consistent with the OTC $\mathrm{HCl}$ assay

\section{Quantification of the OTC $\mathrm{HCl}$ residues}

The samples residues levels are calculated according to Pananookooln (2007)

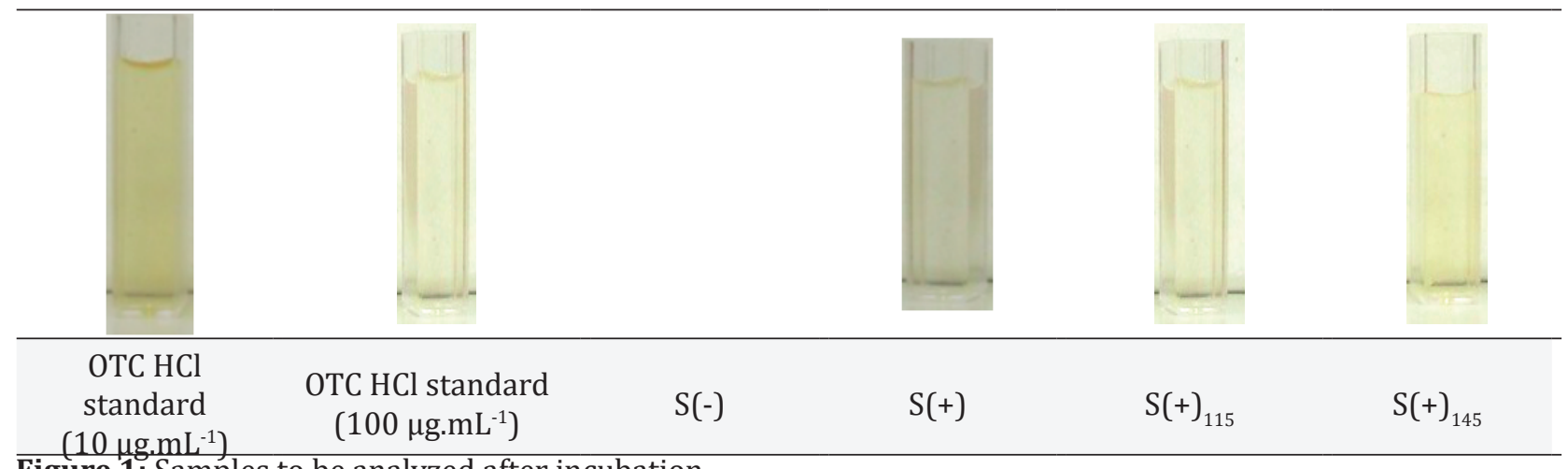

Figure 1: Samples to be analyzed after incubation

Table 3: Samples absorbances

\begin{tabular}{ccccccc}
\hline & $\begin{array}{c}\text { OTC HCl standard } \\
\left(10 \mu \mathrm{g} \cdot \mathrm{mL}^{-1}\right)\end{array}$ & $\begin{array}{c}\text { OTC HCl standard } \\
\left(100 \mu \mathrm{g} \cdot \mathrm{mL}^{-1}\right)\end{array}$ & $\mathrm{S}(-)$ & $\mathrm{S}(+)$ & $\mathrm{S}(+)_{115}$ & $\mathrm{~S}(+)_{145}$ \\
\hline Absorbance & 0.098 & 0.031 & 0.374 & 0.020 & 0.049 & 0.067 \\
\hline
\end{tabular}




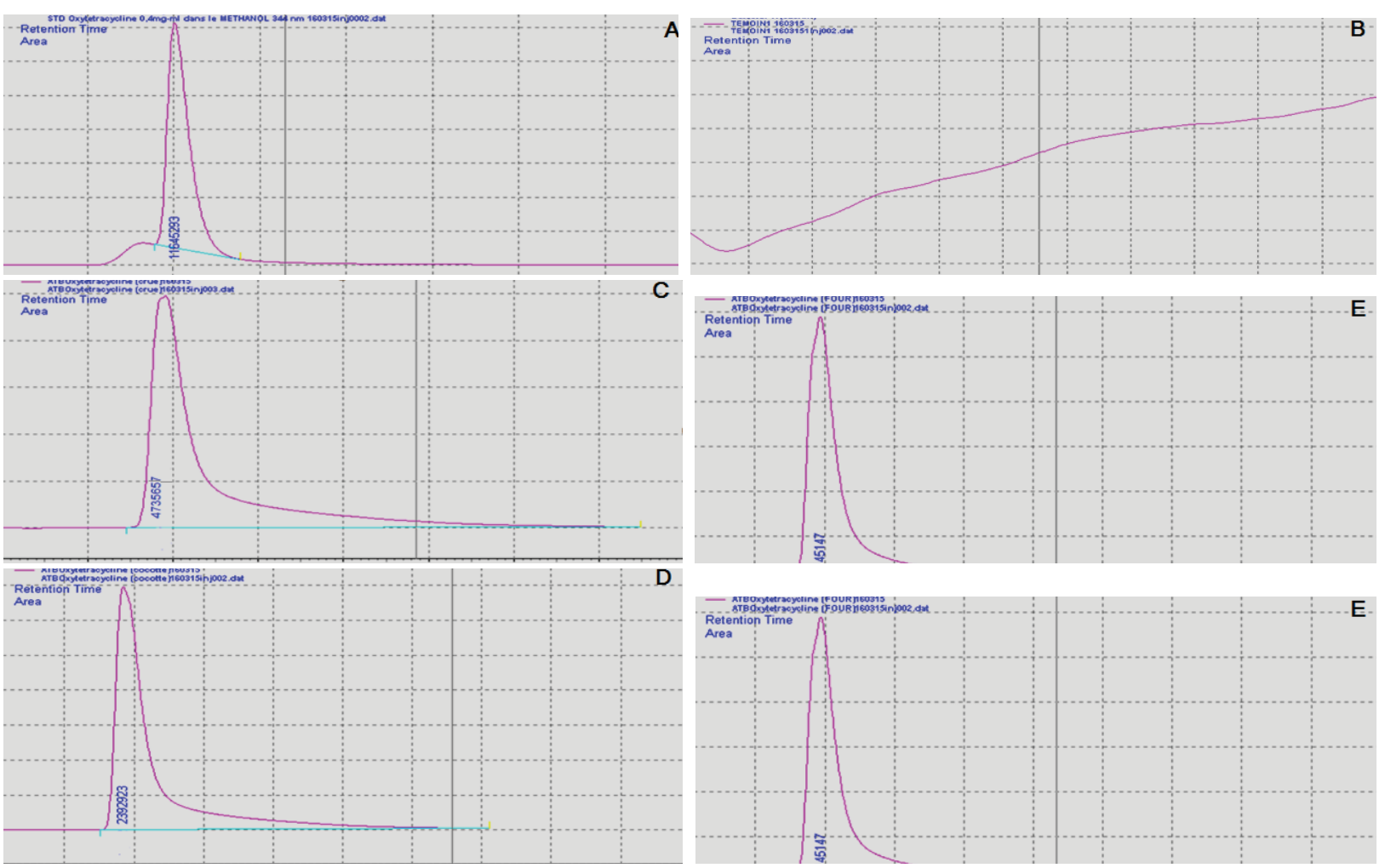

Figures 2: A :OTC HCl standard chromatogram, B : Negative sample S(-) chromatogram, C : Positive sample S(+) chromatogram, D : Positive sample heated at $115^{\circ} \mathrm{C} \mathrm{S}(+)_{115}$ chromatogram, E : Positive sample heated at $145^{\circ} \mathrm{C}$ $\mathrm{S}(+)_{145} \mathrm{~S}(+)_{145}$ chromatogram parameters and confirms the presence of the antibiotic in the analyzed sample.The $\mathrm{S}(+)_{115}$ solution contains an OTC $\mathrm{HCl}$ amount which has given a peak (Figure 2D), area 2392 923, after 1.93 min of analysis.The $\mathrm{S}(+)_{145}$ solution contains an OTC $\mathrm{HCl}$ amount which has given a peak (Figure 2E), area 2145 147, after $1.98 \mathrm{~min}$ of analysis.

Table 4: Data for the calculation of the residues roncentrations (areas, weights and volumes)

\begin{tabular}{ccccc}
\hline & $\mathrm{S}(-)$ & $\mathrm{S}(+)$ & $\mathrm{S}(+)_{115}$ & $\mathrm{~S}(+)_{145}$ \\
\hline $\mathrm{A}_{\mathrm{Ech}}$ & & 4735657 & 2392923 & 2145147 \\
\hline $\mathrm{V}_{\mathrm{Ech}}(\mathrm{mL})$ & 6 & 6 & 6 & 6 \\
\hline $\mathrm{M}_{\mathrm{Fch}}(\mathrm{mg})^{*}$ & 6934 & 6926 & 6917 & 6922
\end{tabular}

Mass of the solution $=$ mass of the minced meat + total mass of solid reagents + mass corresponding to the total volume of the solvents (density*volume)

Table 5: Quantification of OTC $\mathrm{HCl}$ residues

\begin{tabular}{|c|c|c|c|c|}
\hline & $S(-)$ & $\mathrm{S}(+)$ & $\mathrm{S}(+)_{115}$ & $\mathrm{~S}(+)_{145}$ \\
\hline Cooking temperature $\left({ }^{\circ} \mathrm{C}\right)$ & & & 115 & 145 \\
\hline Duration (min) & & & 35 & 20 \\
\hline Quantity $\left(\mu \mathrm{g} \cdot \mathrm{g}^{-1}\right)$ & & 145.7 & 73.7 & 66.0 \\
\hline Residues destroyed by cooking (\%) & & & 49.4 & 54.7 \\
\hline
\end{tabular}

$C_{r}\left(\mu g . \mathrm{mg}^{-1}\right)=\frac{A_{E c h} \times V_{E c h} \times C_{S t d} \times P_{S t d}}{A_{S t d} \times M_{E c h}}$

$\mathrm{C}_{\mathrm{r}}$ : amount of residues in the sample ( $\left.\mu \mathrm{g} \cdot \mathrm{mg}^{-1}\right)$ $A_{\text {Ech }}$ : peak area of the injected sample solution
$\mathrm{V}_{\mathrm{Ech}}$ : volume of the injected sample solution(mL) $\mathrm{C}_{\mathrm{Std}}$ : concentration of the OTC HClinjected standard solution (mg. $\mathrm{mL}^{-1}$ ) $\mathrm{P}_{\mathrm{Std}}$ : standard power OTC $\mathrm{HCl}\left(\mu \mathrm{g} \cdot \mathrm{mg}^{-1}\right)$ 


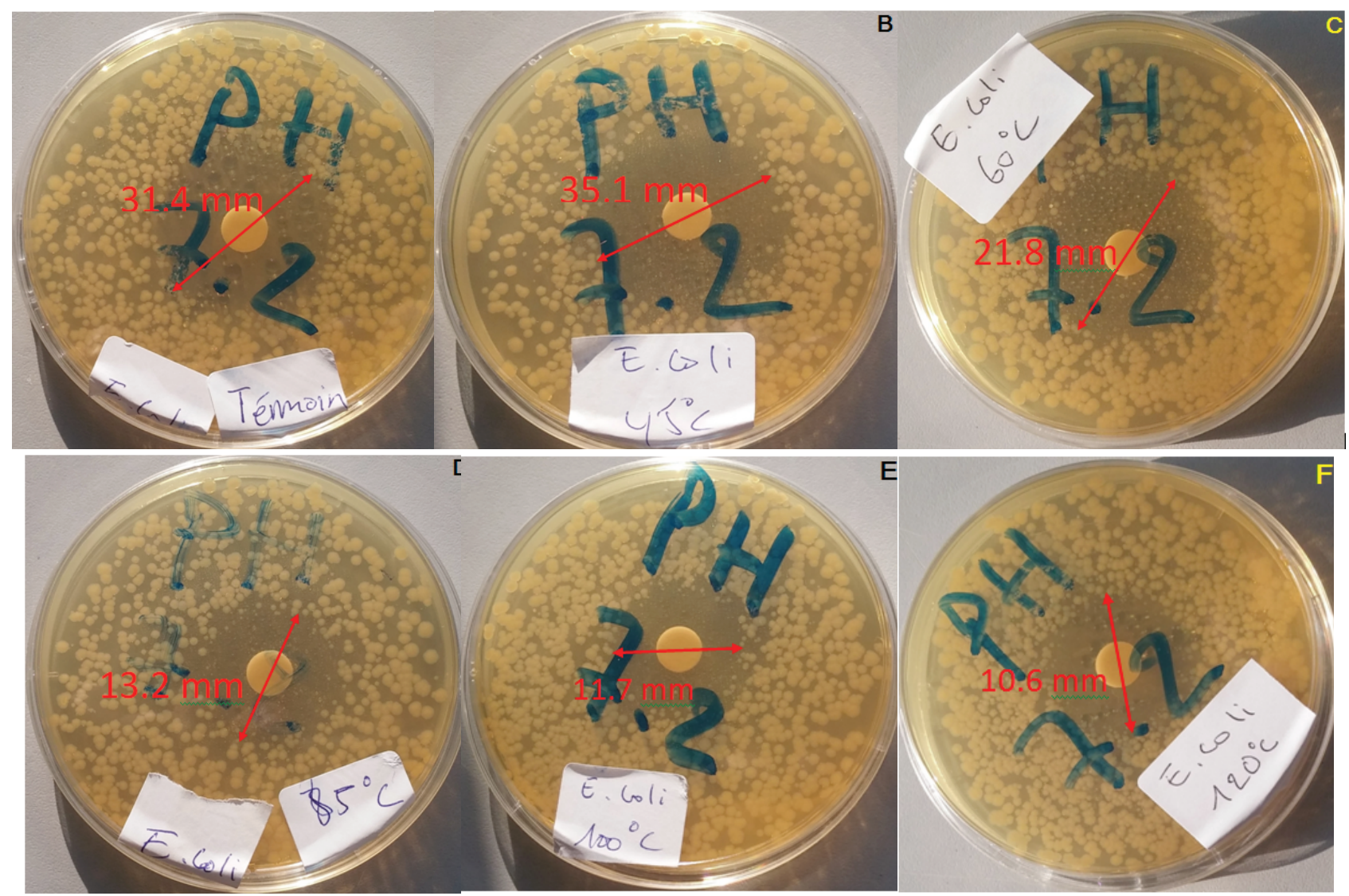

Figures 3: Inhibition zones diameters after incubation. A: Control (31.4 mm), B: Inhibition zone $\left(45^{\circ} \mathrm{C}, 35.1 \mathrm{~mm}\right)$, C: Inhibition zone $\left(60^{\circ} \mathrm{C}, 21.8 \mathrm{~mm}\right)$, D: Inhibition zone $\left(85^{\circ} \mathrm{C}, 13.2 \mathrm{~mm}\right)$, E: Inhibition zone $\left(100^{\circ} \mathrm{C}, 11.7 \mathrm{~mm}\right), \mathrm{F}$ : Inhibition zone $\left(120^{\circ} \mathrm{C}, 10.6 \mathrm{~mm}\right)$

$\mathrm{A}_{\text {Std }}$ : peak area of the OTC HClinjected standard solution

$\mathrm{M}_{\mathrm{Ech}}$ : mass of the sample solution

$\mathrm{C}_{\mathrm{Std}}=0.409 \mathrm{mg} \cdot \mathrm{mL}^{-1}$

$\mathrm{A}_{\mathrm{Std}}=11645293$

$\mathrm{P}_{\text {Std }}=1011.58 \mu \mathrm{g} \cdot \mathrm{mg}^{-1}$

The collected data for the residue levels calculation (areas, weighings and volumes) are given in Table 4 and the results in Table 5.

The peak area of the $\mathrm{S}(+)$ solution has shown the existence of a very high concentration of OTC $\mathrm{HCl}$ residues in raw chicken $\left(>140 \mu \mathrm{g} . \mathrm{g}^{-1}\right)$, that is explained by the strong doses of medicines given to animals before slaughter. The residues levels in the $\mathrm{S}(+)_{115}$ and $\mathrm{S}(+)_{145}$ have confirmed the result of the detection, the decrease of the residues amountwas noticeable: $49.4 \%$ and $54.7 \%$ for the $\mathrm{S}(+)_{115}$ and the $\mathrm{S}(+)_{145}$ samples resoectively.

Results of the OTC $\mathrm{HCl}$ molecule kinetics after heat treatment by the Agar diffusion

The inhibition zones diameters after incubation are visualized in Figures 4A to 4F.
The diameters variation relative to control (in $\%$ ) is given in Table 6.

Inhibition zone with a diameter $>=2 \mathrm{~mm}$ is considered as positive (AFNOR, 2011). The control inhibition zone has given $31.4 \mathrm{~mm}$. Heating the OTC $\mathrm{HCl}$ at $45^{\circ} \mathrm{C}$ for 1 hour has given a diameter larger than that of the control solution, indicating that increasing the ambient temperature can maximize the antibiotic inhibitory effect. On the other hand, heating at $\mathrm{T}>60^{\circ} \mathrm{C}$ during more than $30 \mathrm{~min}$ has allowed the diameter (inhibitory effect) to be gradually reduced up to $66.2 \%$. hence, it is easy to conclude that the $\mathrm{OTC} \mathrm{HCl}$ is thermo-degradable and a treatment at $85^{\circ} \mathrm{C}$ for $50 \mathrm{~min}$ is sufficient to destroy more than half of its initial amount.

\section{Discussion}

In view of the results, the turbidity of the negative sample solution has shown that it did not contain antibiotic residues. However, the uncooked positive sample has shown a slight disturbance, evidence of a large quantity of 
Table 6: Inhibition zone diameters according to temperature and heat exposure duration

\begin{tabular}{ccccccc}
\hline & Control & Tube 1 & Tube 2 & Tube 3 & Tube 4 & Tube 5 \\
\hline $\mathrm{T}\left({ }^{\circ} \mathrm{C}\right)$ & & 45 & 60 & 85 & 100 & 120 \\
\hline Duration $(\mathrm{min})$ & & 60 & 55 & 50 & 40 & 30 \\
\hline Diameter $(\mathrm{mm})$ & 31.4 & 35.1 & 21.8 & 13.2 & 11.7 & 10.6 \\
\hline Variation $(\%)$ & & +11.8 & -30.6 & -58.0 & -62.7 & -66.2 \\
\hline
\end{tabular}

antibiotic. For $\mathrm{S}(+)_{115}$ and $\mathrm{S}(+)_{145}$ samples, the cloudiness is much less obscure than that of the negative sample, evidence of antibiotic levels $<100 \mu \mathrm{g} \cdot \mathrm{mL}^{-1}$. One explanationis that cooking (heat) has affected the initial antibiotic content of these samples, so the inhibitory effect decreased by destruction or transformation of the OTC molecule. To date, there are no similar studies that have used the turbidimetry technique in that sense. In reverse phase HPLC, the plots of the positive meat samples gave peaks consistent with the detection parameters of the OTC HClantibiotic. No peak was recorded for the negative sample which have confirmed that it was free of residues. There have been a decrease of residues concentrations between the uncooked and the cooked samples, $-49.4 \%$ and $-54.7 \%$ at $\left(115^{\circ} \mathrm{C}, 35 \mathrm{~min}\right)$ and $\left(145^{\circ} \mathrm{C}\right.$, $20 \mathrm{~min}$ ) respectiely (Table 5).This highlight the noticeable effect of cooking on the OTC HClmolecule. According to Ibrahim and Moats (1994), cooking for more than $30 \mathrm{~min}$ at $100^{\circ} \mathrm{C}$ completely degrades OTC residues. Our results have shown that cooking at $115^{\circ} \mathrm{C}$ for $35 \mathrm{~min}$ destroys almost $50 \%$ of the residues, which is consistent with the results of Van Egmond et al. (2000) who have found an incomplete residues destruction (53\%), and their relative stability even if they undergo a cooking procedure at $130^{\circ} \mathrm{C}$ for 20 min.Nguyen et al. (2014) have found that cooking at $100^{\circ} \mathrm{C}$ for 15 min reduces the meat OTC content by $43 \%$ and generates adegradation product, $\alpha$-apo-OTCstated inactive and with no danger to the body. Both boiling and microwave treatments resulted in significant changes in OTCs and apo-OTCs concentrations. The formations of apo-OTCs, as well as reductions of OTCs, were dependent on the time of thermal treatments (Nguyen et al., 2015). According to Abu-Raya et al. (2013), OTC residues are thermally unstable and a proper meat cooking over $140^{\circ} \mathrm{C}$ for $20 \mathrm{~min}$ can avert the hazard what is similar to our results, baking at $145^{\circ} \mathrm{C}$ for $20 \mathrm{~min}$ having decreased the initial amount of residues by almost 55\% and according to Ezenduka.et al. in 2018 more than $70 \%$ of initial concentration destroyed after heating at $100^{\circ} \mathrm{C}$ for $40 \mathrm{~min}$. In the heat treatment (Agar diffusion method), the gradual change in colorprobably indicates a change of the molecule in its three-dimensional structure or a fractionation into other compounds which is actually advanced by Kuhne et al. (2001).

The higher inhibition zone produced by the heated solution at $45^{\circ} \mathrm{C}$ relative to control $(+11.8 \%$, Table 6$)$ shows that the inhibitory effect is more important at this temperature. The zones shrink and the inhibitory effect decreases above $60^{\circ} \mathrm{C}$. The inhibition zones diameter decreases gradually as the temperatute increase and the cooking time decrease, reaching $66.2 \%$ relative to control inhibition zone. These variations have highlited the negative correlation between the HTC OTC inhibitory activity and the temperature.

Hassani et al. (2008) stated that heating above $100^{\circ} \mathrm{C}$ for quite long periods (30 to $40 \mathrm{~min}$ ) decreases the initial concentration but with negligible percentages $(\geq 2 \%)$, they suggest thathigh temperature treatments (UHT) are more effective than household cooking procedures in eliminating the risk of antibiotic residues in meat. In contrast, Hsieh et al. (2011) founded that a contanct heating temperature for 35 min reduced by $60.5 \%$ the OTC inhibitory effect, percentage comparable to $62.7 \%$ of initial concentration destroyed after heating at $100^{\circ} \mathrm{C}$ for $40 \mathrm{~min}$ in our study. Kuhne et al. (2001) have found that the tetracycline (TTC) effect can increase after heat treatment at $100^{\circ} \mathrm{C}$, which is due to the appearance of a degradation product, anhydro-TTC, more toxic than the parent compound, but which also degrades into inactive compounds, epianhydro-TTC over $120^{\circ} \mathrm{C}$. This 
was the case in our study, the heating of OTC $\mathrm{HCl}$ at $45^{\circ} \mathrm{C}$ increasing by more than $11 \%$ the inhibitory effect, but which gradually dropped as the temperature continued to rise(Ambrozini et al..2016).

Our results are in agreement with those of Van Egmond et al. (2000), Abu-Raya et al. (2013), Nguyen et al. (2014) and Hsieh et al. (2011), and have confirmed that OTC HCl underwent significant but not complete degradation when heated. These results, however, are in contradiction with those of Ibrahim and Moats (1994).

In view of the kinetics results and those of the Agar diffusion method, it should be noted that the heat began to act positively on the moleculethen negatively as the temperature increases. Indeed, the temperature first has acted positively on the inhibitory effect, its level being suitable for the germs development. Then, the inhibitory effect decreased when this one increased and beyond $100^{\circ} \mathrm{C}$, the effect was greatly reduced, cause ofthe OTC molecule destruction in apparently more toxic elements. The fact remains that the molecule and its transformation effects must be the subject of further study to provide answers to many questions which remain in suspense.

\section{Conclusion}

Within sight of the results of the kinetics and those of the method in diffusion on agar, it should be noted that heat acts on the molecule on levels of temperature positively at the beginning then negatively as the temperature augment. Indeed temperature A acts positively on the inhibiting effect corresponding to a suitable temperature with the development of the germs. Then the inhibiting effect decreases when the temperature augment and beyond $100^{\circ} \mathrm{C}$ the effect is largely tiny room because of the destruction of the molecule of the OTC in elements apparently more toxic; But to become to it molecule and the effects of its transformation must be the subject of a thorough study in order to bring brief replies to much of questions.

\section{References}

1. Abou-Raya S, Shalaby A, Salama N, Emam W, Mehaya F (2013). Effect of Ordinary Cooking Procedures on Tetracycline Residues in Chicken Meat. J Food Drug Anal, 21:80-86.
2. Ambrozini B, Cavalheiro ETG (2016). Thermal decomposition of tetracycline and chlortetracycline. $J$ Anal Appl Pyrol, $118: 317-324$

3. Aggarwal S, Rajput YS, Singh G, Sharma R (2015). Synthesis and characterization of oxytétracycline imprinted magnetic polymer for application in food. Applied Nanoscience 6(2):209-214.

4. Coustès $\mathrm{T}$ (2016). Loi d'avenir agricole, réglementation du médicament vétérinaire et lutte contre l'antibiorésistance. Thèse de doctorat. Ecole nationale vétérinaire d'alfort.la faculté de médecine crétell.106p.

5. Cetinkaya F, Yibar A, Soyutemiz GE, Okutan B, Ozcan A, Karaca MY (2012). Determination of tetracycline residues in chicken meat by liquid chromatography-tandem mass spectrometry. Food Addit Contam B, 5(1) :45-49.

6. Ezenduka EV, Okorie-kanu OJ, Nwanta JA (2018). Effect of temperature (cooking and freezing) on the concentration of oxytetracycline residue in experimentally induced brids. 11(2): 167-171.

7. Hassani M, Lazaro R, Perez C, Condon S, Pagan R (2008). Thermostability of oxytetracycline, tetracycline, and doxycycline at ultrahigh temperatures. J Agr Food Chem, $56: 2676-2680$.

8. Hsieh MK, Shyu CL, Liao JW, Franje CA, Huang WJ (2011). Correlation analysis of heat stability of veterinary antibiotics by structural degradation, changes in antimicrobial activity and genotoxicity. Vet Med-Czech, 56:274-285.

9. Ibrahim A, Moats WA (1994). Effect of cooking procedures on oxytetracycline residues in lamb muscle. J Agr Food Chem, 42 :2561-2563.

10. Jawetz E (1999). Medical Microbiology, Bookstore Maloine, Paris, p. 141.

11. Jorgensen HL, Schulz E (1985). Turbidimetric measurement as a rapid method for the determination of the bacteriological quality of minced meat. $I$ JFoodMicrobiol, 2, 177183.

12. KühneM, Hamscher G, Körner U, Shedl D, Wenzel S (2001). Formation of anhydrotetracycline during a high-temperature treatment of animal-derived feed contaminated with tetracycline. Food Chem, 75: 423-429.

13. Li R, Zhang Y, Lee CC, Liu L, Huang Y (2011). Hydrophilic interactionchromatography separation mechanisms of tetracyclines on amino-bondedsilica column. J Sep Sci, $34: 1508-1516$.

14. Meyer V (2010). Practical High Performance Liquid Chromatography, $5^{\text {th }}$ edition. John Wiley \&Sons, 428 pages.

15. Nguyen VH, Nguyen VT, Li CB, Zhou GH (2015). The degradation of oxytetracycline during thermal treatments of chicken and pig meat and the toxic effects of degradation products of oxytetracycline on rats. J Food Sci Technol, 52(5) : 2842-2850.

16. Shahid MA, Siddique M, Abubakar M, Asif M, Arfan A (2007). Status of Oxytetracycline Residues in Chicken 
Meat in Rawalpindi/Islamabad Area of Pakistan. Asian J Poul Sci, 1:8-15.

17. Van Egmond HJ, Nouws JFM, Schilt R, van LankveldDriessen WDM (2000). Stability of antibiotics in meat during a simulated high temperature destruction process. Euro Residue 4: 430-437.
18. VanHue N, VanToan N, ChunBao L, Guang Hong Z (2015). The degradation of oxytetracycline during thermal treatments of chicken and pig meat and the toxic effects of degradation products of oxytetracycline on rats. J Food Sci Technol. May, 52(5): 2842-2850. 